\title{
Transformational Developments at the Interface of Race, Sport, and the Collegiate Athletic Arms Race in the Age of Globalization
}

\author{
Harry Edwards \\ University of California, Berkeley
}

This essay includes a survey and analysis of social, cultural and political factors and forces contouring and configuring the state and trajectory of African-American Sports involvement as we enter the second decade of the 21 st Century. These factors include the circumstances and conditions of the traditional Black community; Black educational challenges; the issue of race, justice, and power; and the "collegiate athletic arms race" in the age of globalization in sport and society.

In his classic work on American character, culture, and civic organization, Democracy In America, Alexis de Tocqueville wrote in part:

"... as long as the majority is doubtful, one speaks [safely]; but when [the majority] has irrevocably pronounced [a consensus belief] everyone becomes silent and friends and enemies alike seem to hitch themselves together to its wagon... In America, the majority draws a formidable circle around thought. Inside those limits, the writer is free; but unhappiness awaits him if he leaves them...the power that dominates in the United States [manifest in majority opinion] does not intend to be made sport of... The slightest reproach wounds..., the least prickly truth alarms; and one must praise [the consensus] from the forms of its language to its most solid virtues... The majority, therefore, lives in perpetual adoration of itself; only foreigners and experience can make truths reach the ears of Americans" (In Mansfield and Winthrop, pp. 243-245).

I first came upon this passage from the writings of de Tocqueville in 1960 as a freshman scholarship athlete while studying for an American history class. For me, even then (I was seventeen at the time) it provoked thoughts-angry and analytical-concerning why blatantly racist and discriminatory contradictions that I saw so clearly and experienced so intensely in my college community and athletic department were so broadly viewed as beyond the bounds of polite popular discussion, of even academic debate-much less corrective intervention. 
As a "foreigner", as the "other", as an "outsider", as a Black athlete and very serious sociology student on a predominantly White college campus at the onset of the 1960s, I found what I believed to be an institution-wide reluctance to face and address uncomfortable and inconvenient human relations realities-particularly at the interface of sport, race, and community - to be deeply disturbing and increasingly intolerable. Eventually, it was this situation that compelled my role in the "revolt of the Black athlete", in the "Olympic Project for Human Rights", in the establishment of college and professional sports "minority coaches outreach" programs, and other such efforts, along with my contributions in pioneering a new frame of critical research and analysis, the "Sociology of Sport", focusing on the ever evolving state and dynamics of sport in society.

Today, there are crises born of contradictions at the interface of sport, race, and society that are no less stark and disturbing than those of the 1960s. And there also has been a corresponding reluctance, both within and beyond the institution of sport, to acknowledge and address existing and emerging realities associated with these contradictions. To assess these crises and their trajectories going forward, it is necessary to understand the roots of their form and dynamics in the past.

\section{Integration and Disintegration}

Under the auspices of post-World War II Black and liberal White American protests and demands for an end to segregation in combination with the global challenges posed by communist states to Western capitalist interests and democracies (particularly relative to influence over resource-rich, largely non-White developing nations), beginning in 1946 America embarked upon a broad-scale reversal of official laws and defacto policies mandating race-based segregation and discrimination. In sport, there was the additional — and I believe determinant-business motivation of gaining access to a largely untapped Black athlete talent and fan pools in the wake of a White talent shortage following the War. This confluence of social and political pressure and business interests precipitated the reintegration of Black players into the National Football League in 1946 (marking the first time since 1934 that a Black player had taken the field as part of an NFL team) and into Major League Baseball in 1947 and the National Basketball Association in 1950. Under the impetus of the 1954 Brown v. Board of Education, Topeka, Kansas Supreme Court edict mandating the desegregation of public schools, traditionally White high school and college athletic programs were also positioned to take advantage of the newly accessible Black athlete pool-principally in the revenue producing sports of basketball and football. Again, the major motivating forces here were business and politics-not brotherhood.

Two features of this integration process are of seminal importance here. First, in both sport and society integration was largely one-way and selective, meaning those Blacks "integrated" had to be on or at least within sight of the "mobility ladder" out of the Black community, as opposed to two-way and structural as had been envisioned by most in Black society, and most certainly by most people involved in what had developed under "separate but equal" policies into a paralleled Black sports institution. Negro League owners such as Rube Foster argued vociferously against the method of integration only to be castigated by pro-integration voicesincluding the Black press. But as became apparent, the fears and concerns of the "Rube Fosters" of the era were not unfounded. 
Here we must understand that the forces driving this dialogue and debate were not just issues of conflicting politics and preferences. This development was as much a product of intergroup power dynamics as of design. Where change mandates emerge out of diverse circumstances and developments - as opposed to fundamental and functional intergroup power equality and exchange-regimens instituted on behalf of the subordinate group will inevitably trend toward the most parsimonious and least costly policy and action options relative to dominant group status quo interests. So while the racial integration of Major League Baseball was one-way (from the Negro Leagues) and selective (Black players only) the "integration" of the National Football League with the equally powerful American Football League was two-way and structural — which is to say that not only were AFL players integrated into the NFL, but entire AFL franchises merged under the NFL banner.

Furthermore, because the intergroup power imbalance that largely predisposed the method of integration is residual in the functioning of those integration remedies established, there has evolved a persisting "pressure" toward the erosion of subordinate gains. For such subordinate groups, the challenges posed by these circumstances are dynamic, diverse, and recurring; the struggle to sustain and advance change, therefore, is perpetual; and there can be no final victories in the absence of enduring power equality.

The method of implementing integration fostered the substantial abandonment of traditional Black communities and institutions by increasing numbers from among the more skilled and the upwardly mobile working and middle classes as they sought better competitive circumstances and greater advancement opportunities in and on the periphery of White society and its institutions. In the process, they took with them their visibility and family standing and stability; their entrepreneurial and organizational skills and capacities; their wealth; their civic, cultural, and political associations; their contacts and connections-however limited or tenuous-with outside mainstream interests and institutions; their "can-do" values, work ethic, aspirations, and hopes; and their more expansive world views-that capacity to dream broadly of a Black role and relevance beyond the confines of the Black community.

The second feature of this integration process of direct significance here is that it eventually gave rise to what I termed in 1967 a "plantation structure" of mainstream sports organization. As I stated at the time, "By not integrating Negro League owners, managers, and associated staffs, by not integrating Black collegiate athletic directors, head coaches, media directors, etc. along with "blue chip" Black athletes into mainstream traditionally White sports structures, most specifically in the revenue-producing sports of basketball and football, America has replaced segregated sports with a plantation structure of sports organization wherein Whites have exclusive control of decision-making and authority positions while Blacks are consigned to the least powerful, most exploited, and most expendable position - that of athlete. We have been relegated to the status of "20th Century Gladiators" in the entertainment and money-making service of White institutions ${ }^{1}$.

After observing the evolution of this "plantation structure" over subsequent years, I arrived at the corollary conclusion that

"what happens to the subjugated racial minority in the nominally integrated and systematically exploitive system does not just happen to them; it just hap- 
pens to them first and worst. Ultimately, it negatively influences the fate and fortunes of all who share a comparable position with that minority".

It was therefore with some sense of validation that I read the sentiments of one of the staunchest critics of my use of the "plantation structure" analogy in the 1960s, Mr. Walter Byers (N.C.A.A. President 1951-1988), who wrote in 1997:

“Today the N.C.A.A. President's Commission is preoccupied with tightening a few loose bolts $\mathrm{n}$ a worn machine, firmly committed to the neo-plantation belief that the enormous proceeds from College games belong to the overseers (administrators) and supervisors (coaches). The plantation workers performing in the arena may only receive those benefits authorized by the overseers" (In Whitlock, 2010).

Mr. Byers acknowledged virtually every argument that I'd put forth thirty years earlier-except that a disproportionate number of the workers, and the stars among them, who produce those "enormous proceeds" are Black.

When I first expressed these sentiments in 1967 they were, to say the least, not well received. Outside of the deep South, integration in whatever guise was simply not to be questioned — especially by a "Negro." To apply segregation or a slavery-era analogy in describing any integration outcome was viewed as outrageous.

Both the out-migration of the more affluent classes from the traditional Black community and the plantation structure of sports organization, in combination with emerging broader societal developments, have inevitably generated consequences barely hinted at before the onset of the last quarter of the 20th Century. Denied the leadership involvement and influence of its absent "integrated" classes, traditional Black communities began to dis-integrate. Left out of the mainstream integration process, these communities were soon left behind. Particularly in more densely populated urban areas, too often they fell into deepening institutional dysfunction, material deterioration, and civic disarray while the people historically dependent upon their viability spiraled into ever more crippling desperation and hopelessness. Due largely to the method - not the fact - of racial integration, access to both the American mainstream and the "American dream" loomed ever farther beyond the horizon of perceived possibility, more remote and seemingly unachievable than even before desegregation for millions relegated to these Black urban centers and neglected rural backwaters.

\section{From Disintegration to Dysfunction}

Today, there is no denying the ample evidence supporting negative assessments and perspectives relative to conditions in traditional Black communities. While from 2008 to the present America has been experiencing the most devastating economic conditions in almost 80 years, the economic circumstances of urban Black communities have approximated those conditions and worse at least since the recession of the 1980s. Since that time substantial numbers of people-particularly teenaged and young adult Black males-have been driven to ever greater reliance upon the underground and underworld economies. So the $16.1 \%$ Black unemployment rate reported in 2009 Department of Labor statistics (nearly twice the national unemployment rate), as disturbing as it is, in reality grossly underestimates the true scale 
of mainstream unemployment in these communities. In fact, in many urban areas, the real rate probably exceeds $30 \%$, since so many people were either never in the work system, were under-employed, or long ago gave up the search for mainstream employment. The impact of this situation on Black youths has been devastating.

With no vision or hope of inclusion in the economic mainstream beyond dreams of becoming rap artists, professional athletes, or taking some other high profile, low probability, ostensibly talent-based career path, too many Black youths' value on education is severely diminished. This, in combination with poorly resourced, deteriorating urban educational infrastructures and environments has resulted in Black student drop-out rates that in 2008 were approaching $40 \%$ nationally according to Department of Education figures with many school districts experiencing even higher rates (Wetzel, 2008, p. A6).

This situation, of course, has precipitated not only greater mainstream entrylevel unemployment among Black youths and long-term unemployability among Black young adults, but it has increased Black involvement in the criminal justice system as these groups have come to rely increasingly upon the underground and underworld economies to sustain themselves and meet their needs. Nationally, $43 \%$ of the 2.1 million people incarcerated in the United States are Black, mostly males, although Black males constitute less than $7 \%$ of the total U.S. population (Alzenman, 2007). In California over a quarter of Black males aged 15-34 are under the control of the courts - either under suspicion and investigation, under indictment, under arrest, incarcerated, or out on bail, probation, or parole.

And California is not exceptional. In my home state of Illinois, over the first decade of the 21 st Century Blacks have been $50 \%$ of youths arrested and $55 \%$ of youth incarcerated; for drug-related (underworld economy) crimes, 59\% of youths arrested and $88 \%$ of youths sentenced to prison have been Black, while $85.5 \%$ of youths tried as adults have been Black. In Louisiana, where only a third of the state's youths are Black, Black youths have accounted for $78 \%$ of the young people confined in correctional facilities (Leonard and King, 2010, p. 23). And with so many young Black people in particular entering and returning from prison, it was only a matter of time before prison cultural features began to displace established cultural traditions in traditional Black communities. The misogynistic, vile, "gangsta" language, the tattoos, the dress styles, and other cultural accoutrements associated with the "hip hop" generation more often than not have their foundations not in the hip hop music culture but in prison culture.

Quite simply in the wake of integration and institutional deterioration in the Black community, traditional Black culture is being increasingly highjacked by prison culture.

And it is not just in the realms of education, employability, and cultural viability that the traditional Black community finds itself in the throes of crisis and decline.

Many of our urban centers exist in what only can be characterized as a state of undeclared urban warfare. Consider this situation in comparison with U.S. casualties over the first five years of the Iraq and Afghanistan wars. Defense Department statistics indicate that a combined total of just over 5,000 Americans of all races, ethnicities and genders died in combat from all methods and means of assault in these war zones. According to figures released by the Centers for Disease Control (C.D.C.) and published in the New York Times, based upon Black homicide rates by gun fire alone over that same five-year period over 27,000 Black males would 
have died, nearly 11,000 of them being 18-24 year olds (Marsh, 2007, p. 14). And because the overwhelming majority of these deaths occurred at the hands of other Black males, there is a double lose to the Black community - to the cemetery and to the prison system. According to the latest C.D.C. statistics, homicide is the leading cause of death for 10-24 year-old African-Americans nationally (that is, the 5th grade through college athlete development and sports participation years). But to put a finer, more definitive point on the situation, consider the realities of just one city and its urban Black community - the city of Oakland, California. This is the city that produced Bill Russell, Frank Robinson, Rickey Henderson, Cito Gaston, Curt Flood, Gary Payton, Jason Kidd and other great athletes over the years. It is also a city where I was Director of Parks for three years from 2000 to 2003 and, so, I got to know its circumstances extremely well, up close and personal, so to speak. The front page headline of the Thursday, October 21, 2010 Oakland Tribune says it all:

"Living in a war-zone neighborhood: Some overseas combat areas aren't as dangerous as violence-plagued communities in the U.S., study says" (Johnson, 2010, p. 1)

The article goes on to state that Black males in certain neighborhoods of Oakland are 16 times more likely to die violently than their White peers. Further, over the last nine years more than 1000 people have been killed in Oakland, (over 96\% of them young Black males). That bleak statistic is important in and of itself, but again, when juxtaposed against the fact that the toll of American combat deaths in the Afghanistan War over that same nine years as 996, it projects even more devastating implications. And in Oakland, it is not just that a young Black male has as great a chance of being killed by gunfire on the streets of his own community as he would have of dying in a war-zone outside of Kabul. There are other forces equally rooted in past historical developments that reduce Black life choices and chances.

I have already spoken of the situation that schools so often face in traditionally Black communities. In Oakland, not surprisingly, the areas hardest hit by violence are those where schools are in the most dire condition and where community centers and parks have either been closed due to budget considerations or are too crime-ridden and dangerous to use. Violence in these areas is pervasive and recurring, with perpetrators often using A-K $47 \mathrm{~s}$, the weapon of choice among guerrilla movements and insurgencies around the world.

And lest it be presumed that this violence is simply a West Coast phenomenon, consider the observations of Willie Randolph, the baseball great. When he goes back to Brooklyn, N.Y. where he grew up, he invariably has occasion to pass Betsy Head Park where he learned to play the game of baseball. According to an article written for the New York Post, what he sees sickens him.

"Crack addicts have taken over the park, and there's no grass. We used to play baseball there, and now there's just weeds and broken Whisky bottles. It's too dangerous for kids to play there. It's sad" (Willis, 2003, p. 5).

Deteriorating and violent circumstances afflict traditional Black communities nationwide, from coast to coast, with little expectation from residents that the situation will be remedied any time soon. 
Hard economic times, of course, have exacerbated the devastation faced by Black communities from Oakland to Brooklyn. They become "food deserts", where supermarkets, fresh vegetable and fruit outlets, and family-style restaurants have refused to locate. Even medical clinics, dental care establishments, legal offices, and other professional services enterprises have long since abandoned many such areas.

The price paid for such lack of services has been high. Where healthy food outlets have disappeared, fast food and junk food businesses have moved in. In a study of Alameda County where Oakland is located and is the principal residential area of its largest Black population, $30 \%$ of Black men are obese with another 25-35\% seriously overweight; $32 \%$ have high blood pressure. Black men also have the county's highest death rates due to lung cancer, diabetes, prostate cancer and A.I.D.S., largely due to late diagnosis. (Gronke, 2010, p. A5)

But as tragic as these data are, the evidence is that the health of Black men is getting worse. According to Michael Shaw, Director of the Urban Male Health Initiative, "As unemployment rates continue to go up, as our social safety nets become more and more fragmented, as more and more Black males are impacted by undiagnosed post-traumatic symptoms of violent urban life styles, health issues like hyper-tension, obesity and diabetes will continue to rise."

Again, these are not things that are easily discussed and almost never welcomed in "polite" popular conversation and discourse outside of the traditional Black community. As noted by Ronald Ferguson in his work "Parenting Practice, Teenage Lifestyles, and Academic Achievement Among African American Children".

"Some of these facts, analyses, and conclusions are unflattering. Some readers [or listeners] may cite these findings to rationalize neglectful public policies... [Some] warn that a focus on ways that so many African Americans contribute to our own problems may diminish the degree to which the rest of society accepts responsibility for addressing more deeply rooted causes. [Some] believe that placing Black communities and lifestyles near the center of an explanation for [Black ills] reinforces stigmas and stereotypes and may help solidify what is already an abdication of responsibility by national leaders" (Ferguson, 2007, pp. 18-26).

And, he might have added, an abdication of responsibility by many among several generations of Black leaders. In any event, the point here is not to sort through the mix of neglect and Black culpability, but to portray Black circumstances and analyze their on-going and projected impact.

The possibility, even the high probability that the truth of circumstances in so many traditionally Black communities might reinforce or affirm broadly held stigmas and stereotypes is no more a reason to forgo speaking or writing that truth than it would be to fail to speak or write that truth which contradicts consensus beliefs (de Tocqueville's concern). There is no illusion here that all of the circumstances acknowledged and faced can be changed; but nothing can be changed until it is acknowledged and faced.

\section{Race and Sport: The Price of Dysfunctions}

The current and yet escalating costs of circumstances in traditionally Black communities mandates that these causes be vigorously and honestly addressed. Their 
impact upon the quality of life and life chances in the Black community is clear. But how have this institutional deterioration and cruel disintegration impacted Black sport participation and involvement?

In the Fall, 1998 issue of The Civil Rights Journal, the cover was titled, "Race, Sports and Education: African American Athletes at a Crossroads".

Inside I published an article titled "An End of the Golden Age of Black Sports Participation?" While I did not choose the title, the point of the article was clear: because the Black community is in crisis and at a crossroads, Black mainstream sports involvement is also in jeopardy. When we look at professional sports, the emerging pattern is evident: the Black athlete talent pool is shrinking precipitously.

For example, in the heavyweight division of boxing, between 1960 and 1975 there were at least 15 legitimate champions and contenders for the heavyweight title: Floyd Patterson, Sonny Liston, Muhammad Ali, Joe Frazier, George Foreman, Ken Norton, Eddie Machen, Jimmy Ellis, Jimmy Young, Cleveland Williams, Earnie Shavers, Ernie Terrell, Archie Moore, Buster Mathis, and a sparring partner who couldn't break into the contender lineup, by the name of Larry Holmes. Between 1975 and 1990, that number dropped to three: Larry Holmes, Evander Holifield and Mike Tyson. Between 1990 and 2005, there were still only three, none of whom apparently warranted the cachet or recognizability of past generations of Black heavyweight champions and contenders. So if the likes of James Toney, Chris Byrd, and Shannon Briggs do not immediately come to mind as recognizable faces and boxing figures, it is understandable.

Similarly, in 2010 only 8.2-9.0 (depending on the injury and active rosters) percent of Major League Baseball players were African-Americans (as distinguished from Black players of Latin decent). This is down from 23 to 27 percent over the decade of the 1970s. Even Jackie Robinson's former team, the Dodgers, reflected the trend. At one point, the Dodgers had the same number of African-American players as on the day that Jackie joined the team in 1947- one! As Jackie Robinson's widow, Rachel said as early as 1997_- "the 50th Anniversary of Robinson breaking the color line in Major League Baseball_- "Jackie expected more. We're all disappointed that it has come to this."

Even the N.B.A. is feeling the crisis of the Black athlete. From a high of $82.4 \%$ African-American players in the mid-1980s to $73.2 \%$ in 2009 , the N.B.A. like baseball is filling vacated Black slots with foreign-born athletes. While foreignborn players made up $40 \%$ of the signed talent pool in Major League Baseball and filled $26 \%$ of its roster spots in 2010 , the N.B.A. had the highest number and proportion of foreign-born players under contract in its history-104 players out of approximately 418 athletes under contract.

And what of Black fortunes within the collegiate ranks? In 1987, the N.C.A.A. commissioned its first and still only study of the origins and experiences of Black football and male basketball players at Division I institutions. Published in 1989, it showed that Blacks, as expected, were over-represented as athletes in these two sports. As significantly, the study showed that these athletes came mostly from the lower social-economic strata (49\% from the lowest economic quartile and over $70 \%$ at or below the second quartile, as opposed to $13 \%$ for Whites) and that they arrived on campus less well prepared academically $(58 \%$ at or below 752 on the S.A.T., compared with $19 \%$ of Whites and $61 \%$ with a B- GPA or below as compared with $31 \%$ of Whites). It was also reported that Black football and basketball 
players on overwhelmingly White campuses reported feeling different from other students, existing in racial isolation with little control over their lives. A third of these athletes reported at least six incidents of racial discrimination (Oriard, 2009, p. 154). Clearly, as was the case in the 1960 s, by the 1980 s and to this day, Division I institutions have not figured out how to make a substantial portion of Black athletes part of the total university community or even how to make them feel like they belong on campus.

Under the circumstances, and particularly in light of deteriorating educational and cultural circumstances in the communities that have generated a disproportionately large number of these athletes, why has their overrepresentation on these traditionally White campuses persisted?

\section{Black Male Athletes and the Collegiate Athletic Arms Race}

In the Winter-Spring 1984 issue of the Journal of Sport and Social Issues, I published an article called "The Collegiate Athletic Arms Race: Origins and Implications of the 'rule 48' Controversy" (Edwards, 1984, pp. 4-22) I began the article with the statement that "The passage of Rule 48 by the N.C.A.A. provoked the most heated racial debate within the organization since the onset of...integration. At the core of the controversy are concerns over the legislation's anticipated financial and academic consequences for those Division I institutions which have traditionally set less stringent academic standards for athlete admissions and sports participation" (Edwards, 1984, p. 4).

In short, by 1984 it was clear that the Black athlete had become a major component of the "Collegiate Athletic Arms Race", an arms race that included not only the athlete "big guns" and "aircraft carriers" needed to build winning programs, but the facilities, expanded coaching staffs, and support amenities to recruit and keep successive generations of such athletes.

At the time, I also made another statement: the "Collegiate athletic arms will prove to be ultimately unmanageable, absolutely unsustainable, and it will become increasingly unconscionable as deprived academic departments at Division I colleges and universities stand in ever more stark and disturbing contrast to the opulence of athletic programs and departments."

At the time this article was published, it was ridiculed as "radical rhetoric." Even when my good friend and former colleague, Ira Heyman, then Vice-Chancellor at the University of California, at Berkeley, presented an address warning of the devastating potential of the "Collegiate Athletic Arms Race" at the 1987 N.C.A.A. convention, he was met with "wide-spread skepticism and levity" (in the words of Murray Sperber, author of College Sports, Inc.).

Today, it would be hard to find anyone who believes the existence, challenges, or escalating costs of the collegiate athletic arms race to be matters of dubious or comical concern. The history of this arms race in its current guise goes back to the 1960s and the competition among institutions and conferences for mediagenerated dollars. The separation of institutions into three divisions and then of Division I into I-A and I-AA; the creation of the College Football Association (C.F.A.) in 1976; the Bowl Coalition in 1992; the Bowl alliance in 1995; the 
Bowl Championship Series in 1998; the split between "Major" football conferences and "Mid-Major" conferences; the multimillion dollar head coach contracts and expanded coaching staffs; the on-going expansion of conferences to include more institutions; and grossly expanding athletic budgets, facility debt service obligations, and financial burdens upon tuition and general fund resources are all manifestations of what are generally referred to today as "arms race issues". And, notwithstanding all of the academic reform, support, and social-cultural adjustment efforts made to accommodate the needs, interests, and developmental challenges posed by the Black athlete, it has been the "arms race" efforts to recruit competitive basketball and football talent that has kept the Black athlete on Division I campuses in disproportionately high numbers. But his days of over representation, like those of so many among his professional counterparts, could be seriously threatened.

\section{The Pressures to Unilaterally Disarm}

First of all, increasing numbers of Division I institutions are likely to follow the lead of the University of California, Berkeley and begin to "unilaterally disarm" relative to athletic budgets. Though it was only a small step (what Walter Byers would undoubtedly have characterized as a "tightening a few bolts in a worn machine") on September 28, 2010, U.C. Berkeley announced that it was reducing its athletic budget — which had required 14 million in subsidies per year-by scrapping 163 athletic scholarships and eliminating five sports programs, including baseball, rugby, men's and women's gymnastics, and women's lacrosse. Most notably, neither basketball-men's nor women's-nor football were on this "hit list", though both departments preemptively suggested cuts that might be made in their budgets. Whether at U.C. Berkeley or elsewhere, without cuts to basketball and football and the debt service that their operations incur, no substantial reduction in the impact of "arms race issues" is likely to occur. In Football Bowl Subdivision (FBS) conferences, for example, median spending per student-athlete far out-strips spending per student in the general academic population, ranging from 4 to 11 times as much. To quote the Knight Commission Report "Restoring the Balance":

\footnotetext{
"At most institutions [athletic costs] require a redistribution of institutional resources...from general university funds, fees imposed on the entire student body, and/or state appropriations. This reliance upon institutional resources to underwrite athletic programs is reaching the point at which some institutions must choose between funding [academics] or the football and basketball teams...It is clear that the spending race that too often characterizes major football and basketball programs is creating unacceptable financial pressures on everyone... The current financial downturn should be a financial wake-up call for everyone. It has significantly refocused academic priorities and even forced some institutions to ratchet back spending on sports- "primarily by paring teams from lower-profile sports. However, even with this new reality, top programs are expected to have athletic budgets exceeding 250 million dollars by 2020, athletic budgets serving an average of only 600 students."(The Knight Commission, 2010, p. 7)
} 
The Knight Commission goes on to recommend that not only so-called "minor sports", but football and basketball costs must also eventually be pared back through such measures as reducing athletic scholarships, reducing the numbers of coaches and support staff, and reducing expenditures and debt service costs incurred though facility and program service up-grades and expansion.

In sum then, along with the tragedies of culturally derailing, academically under preparing, jailing and burying, our prospective Black athletes, we also must now add the growing unsustainability and tenuousness of a collegiate athletic arms race that has functioned to preserve an overrepresentation of Black athletes in the revenue-producing sports of collegiate basketball and football.

And there are two final influences that promise to hasten the pace of a diminution of the Black athlete's presence in big-time collegiate sports programs: globalization and the continuing evolution and impact of the "sports-technology complex".

\section{The Sport-Technology Complex in the Age of Globalization}

In my 1971 dissertation and textbook titled The Sociology of Sport, I presented what I ultimately termed the "First Principle" of the Sociology of Sport:

Sport inevitably and unavoidably recapitulates the structure, dynamics, and character of human and institutional relationships between and within societies and the ideological values and sentiments rationalizing and justifying those relationships.

It should come as no surprise in an era where globalization is a dominant feature in virtually every realm of human institutional endeavor that it is increasingly impacting sport as well. We have mentioned its obvious manifestations in professional baseball and basketball. Globalization is also becoming a major force in boxing where promoters and the entertainment media learned well before the end of the 20th Century that a DeLaHoya-Chavez fight marketed globally (and especially in Latin nations and certain states in the U.S.) could draw a larger paying audience than any Ali-Frazier or Tyson-Holyfield fight ever did.

As globalization proceeds apace, not only will U.S. collegiate sports seek to access global markets and audiences but also global athlete talent pools.

The sports-technology complex will continue as a spur to globalization and, therefore, as a factor hastening a diminution in Black athlete participation in collegiate basketball and even football.

As was the case with the concept of the "collegiate athletic arms race", I have adopted the concept of the "sports-technology complex" from military studies. When President Dwight D. Eisenhower warned of the challenges posed by the "Military-industrial complex", what he was really warning us about was the military-technology complex, since industry devoid of technological development and evolution is stagnant and ultimately impotent. It is the capacity and potential to devise new defense technology that the military finds so seductive in its relationship with industry.

Similarly, sport has been impacted and driven by all manner of technological influences-medical and pharmaceutical technologies, nutritional technologies, 
transportation technologies, communications and information technologies from computers and the internet, to satellite technologies enabling the live real-time broadcast of sports events all over the world. Owing to pharmaceutical, nutritional, and training technologies, athletes are bigger, faster, trained more intensely from an earlier age, and recruited earlier over greater distances than at any other time in the history of modern collegiate sports. In 2007, I reported on a small study that I'd done for the Commissioner of the National Football League showing that offensive linemen listed among SuperPrep Magazine's top 100 California High School 17-19-year-old college recruits that year would enter college on the average weighing only 15.7 pounds less than the average weight for the offensive line of the Super Bowl Champion Indianapolis Colts_-288.5 to the Colts' 304.2 pounds. The thirty-four high school players listed by Rival.com as the top offensive linemen in the nation closed the gap even more, averaging 294.86 pounds-only 9.4 pounds less. In 2008 a 13-year-old was projected as "the leading basketball recruit" for the class of 2014 by another online recruiting service.

Medical technology is revealing consequences of sports participation, in football for example, that appear destined to force changes in the very way that the game is played. This, along with advances in player development and continuing "positional specialization" (one doesn't have to be a football player, only a "rush end" or a "short yardage" or "third-down" running back) means that it is increasingly possible to "choreograph" the development of players with specific skills, and thereby make even so violent and quintessentially American a sport such as football more widely accessible and appealing to prospective participants.

All said, perhaps the situation of Black women in integrated collegiate sports provides the closest indicator of the direction Black males' participation in big time collegiate sports might be headed. Women's sports do not, of course, qualify as "revenue-producing" activities, and so, Black female athletes' representation has not been as protected by way of arms race dynamics.

Since Title IX was applied to collegiate athletics in 1972, Black female participation on traditionally White campuses has risen by $955 \%$ - but only in basketball and track, the two premier sports of women's athletics. Nine out of every ten Black female college athletes participates in one or the other of these two sports. Since the 1990s however, there has been a precipitous decline in the rate of increase in this participation even as the Black population in general has increased. For example, between 1999 and 2005, the number of Black women participating in collegiate sports increased by only 336 athletes as compared with 2,666 athletes for White women. Since Black female athletes also tend to come from traditional Black communities and the lower two quartiles of the economic structure, it should not be surprising that the Black female athlete pool would be likewise diminishing. Similarly, under the auspices of globalization, it is also not surprising that even international female athletes surpassed Black women by gaining 1000 new positions - nearly three times as many slots (Smith, 2007).

And finally, against the background of the analysis presented here, consider the following additional legacy of the past: in a 2001 "turn of the century" study by the children's welfare advocate group Children Now, titled "Foul Play? Violence Gender and Race in Video Games", it was found that of some 1500 video game characters surveyed, 288 were Black males and $83 \%$ of those Black males were portrayed as athletes. With stereotypical bulging biceps and chests, these cyber-characters 
tended to uphold, validate and reinforce an image of Blacks as superior body types more prone to aggressive physicality than cerebral cognition and contemplation. This, among a long list of other studies focused on popular culture perception and projections of Blacks, points toward one unavoidable conclusion: Over the course of the 20th century - in the wake of Black athlete prominence-from Jack Johnson through Joe Louis, Jesse Owens, and Jackie Robinson to Muhammad Ali, Bill Russell, Jim Brown, Michael Jordon, Jerry Rice and Le Bron James-the image, place, and presumed productive potential of Black people has been inordinately defined and culturally configured by a focus upon the development and use of our bodies. The development and use of our minds and intellects through a focus upon educational achievement, particularly since the onset of integration, has been substantially relegated to "Plan B"- - especially in the traditionally Black community.

If present projections persist, over the course of the 21 st century, it will be the development of our minds and intellects through educational achievement that will define and configure our image, place and productive potential as a people - and there will be no "Plan B".

\section{The Need for New Perspectives and Paradigms}

Overall, this admittedly has been a dire and dismal portrait and projection regarding Black collegiate sports participation. But again, if there is any hope of changing the state and trajectory of these developments, it must start with an honest and open acknowledgment and assessment of the situation.

Secondly, we must not make the mistake of looking at developments and realities at the interface of race, sport, and education though what well might be obsolete perspectives and analytical paradigms. Here I use as my guide the challenge of breaking the four-minute barrier in the mile run. For generations this was seen as impossible. Four minutes was viewed as an absolute barrier and boundary of human performance. Yet, after Roger Bannister ran the first subfour-minute mile, in quick succession a number of other runners followed suit. There was clearly no precipitous evolutionary advance in the human physical capacity to run the mile distance. What changed were human perspectives on the possible and commensurate practices.

I find it extremely difficult to believe that a seemingly insurmountable physical barrier that had defied human efforts for decades would constitute a less formidable challenge than social-cultural obstacles to human achievement that are even more clearly of our own creation. In the end, the fate and future of the Black collegiate athlete in America-both male and female-will be determined not by the past history of events, but by that history that we have the will, the courage and the wisdom to make going forward.

\section{Note}

1. This came from my speech at a San Jose State College rally calling for a Black athletes' boycott of the season opening football game between San Jose State and the University of Texas at El Paso in protest of racial discrimination, September 7, 1967. 


\section{References}

Alzenman, N.C. (2008). "U.S. now tops China in inmates", The Washington Post, February 29 , p. 1.

Byers, W. (2010, July). "Unsportsmanlike conduct: Exploiting the student athlete.” In Jason Whitlock, "Expose the NCAA, Not the Athletes" at Fox Sports.com.

de Tocqueville, A. (2000). In Harvey C. Mansfield and Debra Winthrop, (Eds.), Democracy In America.. Chicago: University of Chicago Press.

Edwards, H. (1984). The collegiate athletic arms race: Origins and implications of the 'rule r8' controversy. Journal of Sport and Social Issues, Winter-Spring, 8(1), 4-22.

Ferguson, R. (2007). Parenting practices, teenage lifestyles, and academic achievement among African American children. Focus (San Francisco, Calif.), 25(1), 18-26.

Gronke, A. (2010, June 25,). The Argus, Friday (pp. A5). Black men bearing brunt of recession.

Johnson, S. C. (2010, October 21). "Living in a war-zone neighborhood. Some overseas combat areas aren't as dangerous as violence-plagued communities in U.S., study says." The Oakland Tribune.

Knight Commission on Intercollegiate Athletics. (2010). "Restoring the balance: Dollars, values, and the future of college sports." Miami: Knight Foundation.

Leonard, D. J. and King, C. Richard. (2010). Commodified and criminalized: New racism and African Americans in contemporary sports, Rowman and Littlefield Publishers, Inc.

Marsh, B. (2007, April 22)."An accounting of daily gun deaths," The New York Times, The Nation, p. 14.

Oriard, M. (2009). Bowled over. Chapel Hill: University of North Carolina Press.

Pew Research Center. (2007, November 13). "Blacks see growing values gap between poor and middle class," p. 14.

Smith, L. (2007). Black female participation languishes outside basketball and track. The Chronicle of Higher Education, June, 29.

Wetzel, K.S. (August 2, 2008). Racial gap gets in way of diploma. In Given Half a Chance: The Schott 50 State Report on Public Education and Black Males (pp. A6). The Argus News.

Willis, G. (2003, May 7). "We used to play there." The New York Post, p. 5. 